\title{
Experimental Study on Precast Concrete Shear Walls with Different Hollow Slabs
}

\author{
Qinyan Zhao, Zhongyong Zhang, Jiliang Liu* and Mingjin Chu
}

School of Civil Engineering, Yantai University, Yantai, 264005, China

\begin{abstract}
To study mechanical behaviors of shear walls built with precast two-way hollow slabs, two shear walls with different details of hollow slabs were quasi-statically tested under low cyclic loading. The failure mode was analyzed, which vertical macro-cracks appeared on walls due to the details of hollow slabs. Brittle shear failure can be avoided in terms of the failure behaviors evolved from integral wall to the combination of wall and columns. Test results also show that that dimension of transverse holes can affect compressive capacity of the walls when it is larger than that of longitudinal holes in the hollow slab.
\end{abstract}

Keywords: Compressive capacity, details, hollow slab, mechanical behavior, precast concrete structure, shear wall.

\section{INTRODUCTION}

To meet the demands of housing industrialization in China, assembled monolithic concrete structure is usually adopted [1, 2]. Precast two-way hollow slab shear wall (PTHSW) structure is a new type of assembled monolithic concrete shear wall structure, whose assembly unit is a precast two-way hollow slab with longitudinal and transverse crossing through the holes. After horizontal and longitudinal reinforcement was arranged in the transverse and the longitudinal holes respectively, concrete was poured into the bidirectional holes together with the reinforcement cages of boundary members to form an integral structure. PTHSW structure can be highly industrialized for it is easy to transport and hoist, convenient to connect joints of walls and it also has good structure integrity $[3,4]$.

As shown in Fig. (1), two kinds of hollow slabs A and B are designed to study the effect of different details of the slabs on mechanical behaviors of PTHSWs. The bidirectional holes of slab A are all circular, while the diameter of transverse holes $(89 \mathrm{~mm})$ is less than that of longitudinal holes $(140 \mathrm{~mm})$. For arranging the horizontal reinforcement more conveniently, the transverse holes of slab B are designed square (the longitudinal holes remain circular), moreover, the side-length of the transverse holes $(120 \mathrm{~mm})$ is larger than the diameter of the longitudinal holes $(104 \mathrm{~mm})$.

\section{DESIGN OF SPECIMENS}

Based on the design above, two PTHSWs constructed with hollow slab A and B respectively were tested under low cyclic loading. The cross-section of SW1 is $1440 \mathrm{~mm} \times$ $180 \mathrm{~mm}$, and $1600 \mathrm{~mm} \times 200 \mathrm{~mm}$ for 2-SW1. The aspect

*Address correspondence to this author at the School of Civil Engineering, Yantai University, Yantai, 264005, China; Tel: +86 535 6902606;

Fax: +86 535 6902606; E-mail: lianglju@ 163.com ratio is 1.5 and the same axial fore ratio 0.15 for all specimens. A loading beam and a ground beam were fixed on the wall at two ends to ensure the uniform stress of specimens. Dimensions of the types of walls are shown in Fig. (2) and Fig. (3) respectively.

Under the guideline of the concept 'strong bending capacity and weak shear capacity', the boundary elements of SW1 are reinforced with 5\$25 HRB400 (Hot-rolled Ribbed -steel Bar) longitudinal bars and Ф8 HPB235(Hot-rolled Plain Bar) stirrup hoops at $100 \mathrm{~mm}$ spacing. Meanwhile, the boundary elements of 2-SW1 are reinforced with $6 \notin 25$ HRB400 longitudinal bars and $\$ 8$ HRB400 stirrup hoops at $100 \mathrm{~mm}$ spacing. The volume-stirrup ratios of specimens are $1.5 \%$ and $0.56 \%$, respectively. Reinforcement details of specimens are shown in Fig. (4) and Fig. (5), and some experimental parameters are listed in Table $\mathbf{1}$.

The designed strength grade of precast concrete used in SW1 was 20MPa, while the cast-in-situ was $30 \mathrm{Mpa}$. The concrete designed strength of 2-SW1 was $30 \mathrm{MPa}$. Concrete test cubes and shear wall specimens were made and cured under the same condition [5]. Cubic compressive strength of concrete was tested on the testing day. Averages of measured cubic compressive strength $f_{\text {cum }}$ of concrete are summarized in Table 2. Yield strength $f_{\mathrm{y}}$, ultimate strength $f_{\mathrm{u}}$ and elongation of reinforcement are listed in Table 3. Each dowel-bar reinforcement was inserted at the center of every longitudinal hole to guarantee the connection of ground beam and hollow slab. They were $720 \mathrm{~mm}(385 \mathrm{~mm}$ embedded in ground beam) and $1050 \mathrm{~mm}(650 \mathrm{~mm}$ embedded in ground beam) for two specimens respectively.

\section{TEST SETUP AND LOADING SYSTEM}

The test setup is plotted in Fig. (6). A vertical (axial) load was applied on the top of the specimens by a hydraulic jack (capacity of $3000 \mathrm{kN}$ ) and kept constant during the test; meanwhile a steel distributing beam was placed under the 
Table1. Parameters of specimens.

\begin{tabular}{|c|c|c|c|c|c|c|}
\hline Specimen & $\begin{array}{c}\text { Section } \\
\text { Dimension } / \mathbf{m m}^{2}\end{array}$ & $\begin{array}{c}\text { Height of } \\
\text { Specimen/mm }\end{array}$ & $\begin{array}{l}\text { Longitudinal Bars in } \\
\text { Boundary Members }\end{array}$ & $\begin{array}{c}\text { Stirrups in the } \\
\text { Boundary Members }\end{array}$ & $\begin{array}{c}\text { Horizontal } \\
\text { Distributed } \\
\text { Reinforcement in } \\
\text { Holes }\end{array}$ & $\begin{array}{c}\text { Dowel-bar }^{1} \\
\text { Reinforcement }\end{array}$ \\
\hline SW1 & $1440 \times 180$ & 2160 & $5 \$ 25$ & \$8@100 & \$8@200 & $6 \# 12$ \\
\hline 2-SW1 & $1600 \times 200$ & 2400 & $6 \$ 25$ & \$8@100 & \#10@200 & $10 \# 8$ \\
\hline
\end{tabular}

Table 2. Measured cubic concrete compressive strength of specimens.

\begin{tabular}{|c|c|c|c|c|}
\hline \multirow{2}{*}{ Specimen } & \multicolumn{2}{|c|}{ Hollow Slab } & \multicolumn{2}{c|}{ Cast-in-situ Concrete } \\
\cline { 2 - 5 } & Ages/d & $f_{\mathrm{cu}, \mathrm{m}} / \mathrm{MPa}$ & Ages/d & $f_{\mathrm{cu}, \mathrm{m} / \mathrm{MPa}}$ \\
\hline \hline SW1 & 300 & 41.90 & 125 & 31.59 \\
\hline 2-SW1 & 198 & 42.16 & 142 & 43.56 \\
\hline
\end{tabular}

Table 3. Measured strength of reinforcement.

\begin{tabular}{|c|c|c|c|c|}
\hline Specimen & Reinforcement & $f_{\mathrm{y}} / \mathbf{M p a}$ & $f_{\mathrm{u}} / \mathrm{Mpa}$ & Elongation/\% \\
\hline \multirow{3}{*}{ SW1 } & $\Phi 8^{1}$ & 320 & 435 & 27.5 \\
\hline & $\$ 8$ & 572 & 630 & 17.5 \\
\hline & $\$ 12$ & 493 & 633 & 26.7 \\
\hline \multirow{4}{*}{ 2-SW1 } & $\$ 8^{2}$ & 381 & 569 & 41.3 \\
\hline & $\$ 8^{3}$ & 370 & 567 & 36.3 \\
\hline & $\$ 10$ & 356 & 542 & 43.5 \\
\hline & $\$ 25$ & 447 & 601 & 37.6 \\
\hline
\end{tabular}

${ }^{1}$ Used in hollow slab A. ${ }^{2}$ Used for stirrups in boundary members. ${ }^{3}$ Used for dowel-bar reinforcement.

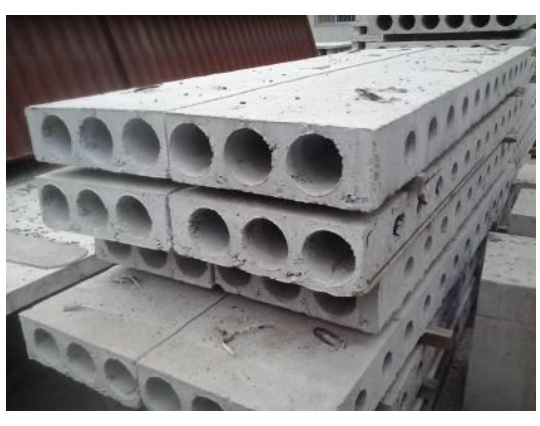

a. Slab A

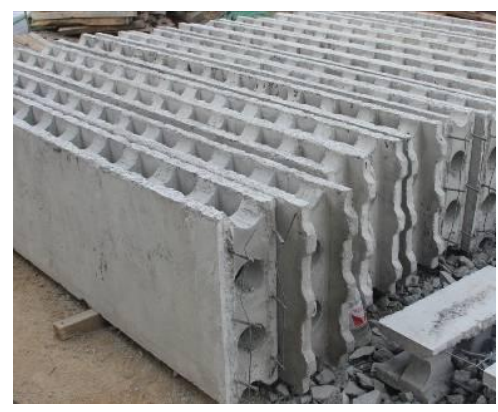

b. Slab B
Fig. (1). Precast two-way hollow slabs.

hydraulic jack in order to maintain compression uniformity along the cross-section of the specimens. A low cyclic lateral load was applied by a hydraulic jack (capacity of 1500 $\mathrm{kN}$ )fixed on a reaction wall and controlled by loadingdisplacement control system. At the early stage of the test, loading control was applied before yield when the first diagonal crack occurred. After that, displacement control was applied with every subsequent cycle repeated twice up to failure, with a maximum displacement of every cycle equal to $2,3,4 \ldots$ times the measured yield displacements. When the top drift ratio increased $1 / 50$ or the wall failed, the test was thought as finished. For the convenience of presentation, the displacement is considered as positive when the actuators pull, and the pull force is considered as positive while the push force is negative. 


\section{EXPERIMENTAL RESULTS AND DISCUSSION}

\section{Crack Pattern and Failure Process}

\section{2-SW1}

Fine horizontal cracks occurred at two toes of the wall when the lateral load reached $-686 \mathrm{kN}$ and $+520 \mathrm{kN}$ and extended in the following cycles. Short minor cracks occurred along the longitudinal holes of slab B at load $581 \mathrm{kN}$. The first diagonal cracks occurred at the lower part of the precast slab in both directions at load $-531 \mathrm{kN}$ and
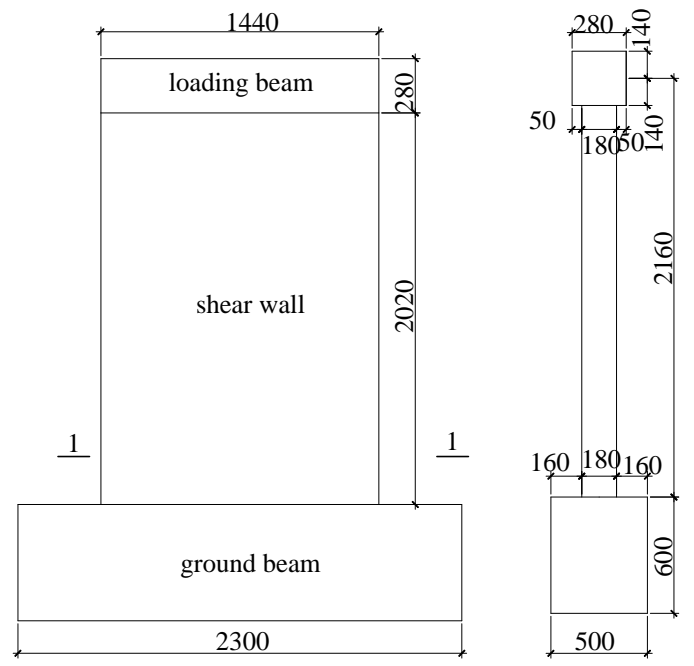

Fig. (2). Dimensions of SW1.

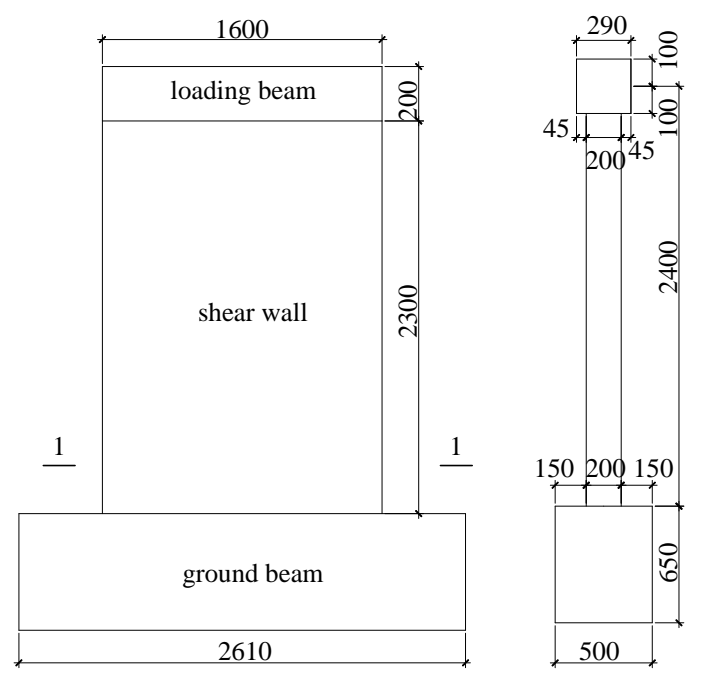

Fig. (3). Dimensions of 2-SW1.

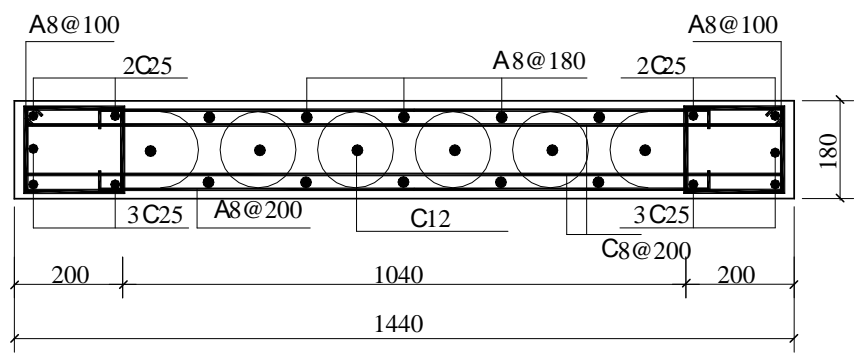

Fig. (4). 1-1 profile for reinforcement details of SW1.

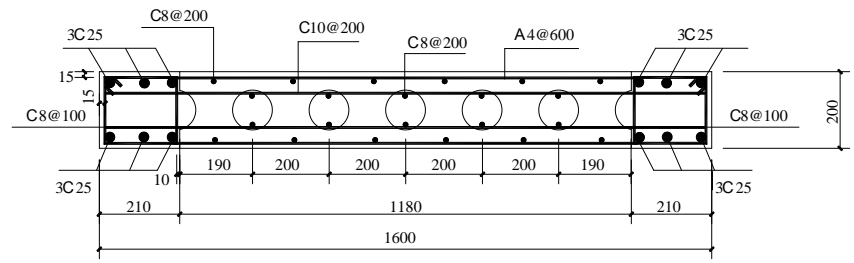

Fig. (5). 1-1 profile of reinforcement details of 2-SW1.

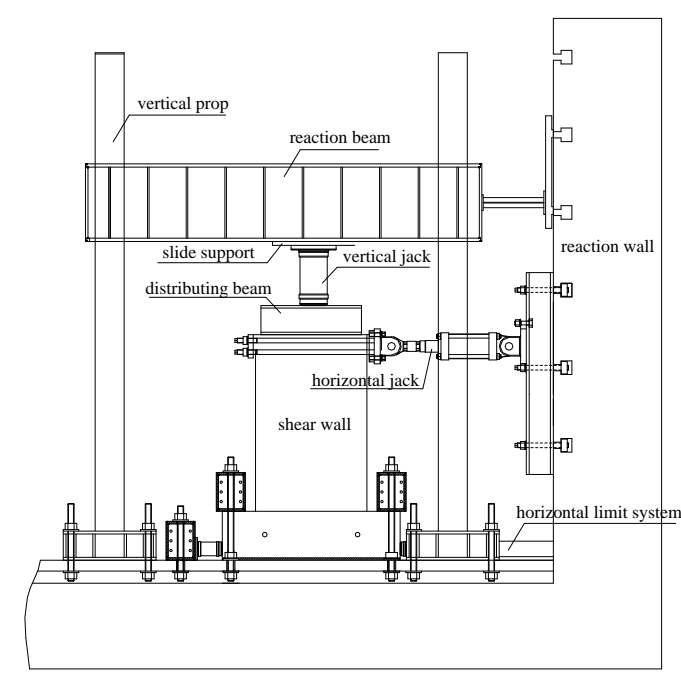

Fig. (6). Test setup.

$+720 \mathrm{kN}$ respectively, hereafter the following cycles were under displacement control. Joints formed by the precast hollow slab and the cast-in-situ concrete boundary members cracked at load $-910 \mathrm{kN}$ and $+676 \mathrm{kN}$, soon extended upward and downward and eventually peeled off rapidly. Before the lateral load increased to the maximum, diagonal cracks in the precast slab and horizontal cracks in boundary members grew rapidly with increase of the lateral load. Multi-strip cross diagonal cracks occurred along two diagonal lines of the wall.

Fig. (7a) illustrates the peak state of 2-SW1. Diagonal cracks increased gradually along diagonal lines with the increase of displacement. The lateral load reached the maximum at load $-1319 \mathrm{kN}$ and $+1342 \mathrm{kN}$.

After that, with increase of the control displacements, concrete around two joints and the cross diagonal lines peeled off with hissing sound in the wall.. When the control displacement reached $-30 \mathrm{~mm}$, some short minor diagonal cracks occurred along the longitudinal distributed reinforcement and concrete around the cracks quickly peeled off then formed vertical macro-cracks. Meanwhile, concrete in a rhombic area formed by cross diagonal cracks in the middle of the wall was crushed partly. Fig. (7b) shows the photo of failure point under the drift ratio $1 / 70$ when the lateral load dropped to $85 \%$ of the maximum load. The middle area concrete was crushed severely and out-of-plane protruded, with strong cracking sound. Reinforcement in the hollow slab exposed and yielded gradually with the increase of displacements. At the end of the test, rhombic concrete failure areas were formed in the middle of the wall with longitudinal distributed reinforcement yielded severely. 
Some slight diagonal cracks occurred on the cast-in-situ concrete columns inside longitudinal holes. Crack occurred at vertical cracks along two boundary members and concrete at two toes of the wall could still intact.

\section{SWI}

The initial failure process of SW1 was similar to 2-SW1. When the lateral load increased $-492 \mathrm{kN}$ and $+600 \mathrm{kN}$, multistrip two-way short minor diagonal cracks occurred along the longitudinal holes of the hollow slab crossed the weakest joints of concrete between longitudinal holes and then formed gradually vertical macro-cracks. At the same time, no visual diagonal cracks occurred on the wall. Vertical macrocracks increased and extended upward and downward before yielding, which divided the wall into some wall-columns. The occurrence of wall-columns changed the development of diagonal cracks of the wall and avoided the brittle shear failure. Fig. (8a) illustrates the peak state of SW1. When the control drift ratio reached $1 / 144$, the lateral load came to the peak value of $-886 \mathrm{kN}$ and $+853 \mathrm{kN}$ respectively.

After that, concrete along vertical macro-cracks peeled off gradually with the increase of displacement. Relative deformation of two sides of the wall increased continually meanwhile the failure behavior changed from integral wall to the combination of wall-columns. Fig. (8b) shows the failure point of SW1 when the drift ratio was 1/100. Concrete along vertical macro-cracks was crushed severely with the increase of displacement. Cast-in-situ columns inside longitudinal holes exposed and became visible. When the test finished, concrete at two toes of the wall and between the vertical macro-cracks was almost intact.

\section{Effects of Different Hollow Slabs on Mechanical Behaviors of Precast Concrete Shear Walls}

Failure processes of these two PTHSWs were different although they both exhibited the similar failure behavior which evolved from integral wall to combinations of wallcolumns. The vertical macro-cracks of SW1 were formed before peak value, which were distributed along the weakest joints of concrete between longitudinal holes; the lateral load was supplied by the combination of wall-columns after peak value, which could avoid the brittle shear failure effectively. The vertical cracks of 2-SW1 were formed along longitudinal reinforcement in the hollow slab after peak value; the performance of the combination of wall and

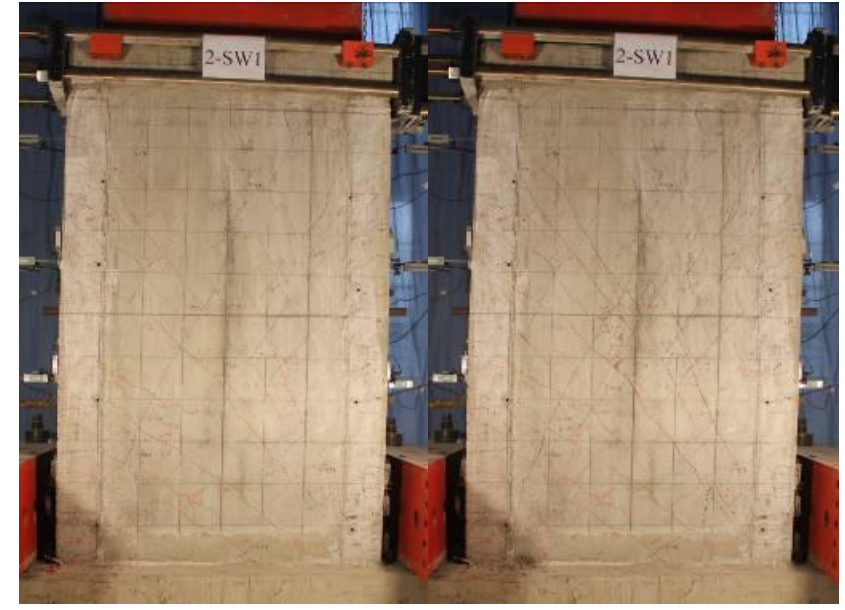

a. Crack pattern at peak load b. The drift ratio 1/70

Fig. (7). Failure process and pattern of 2-SW1.

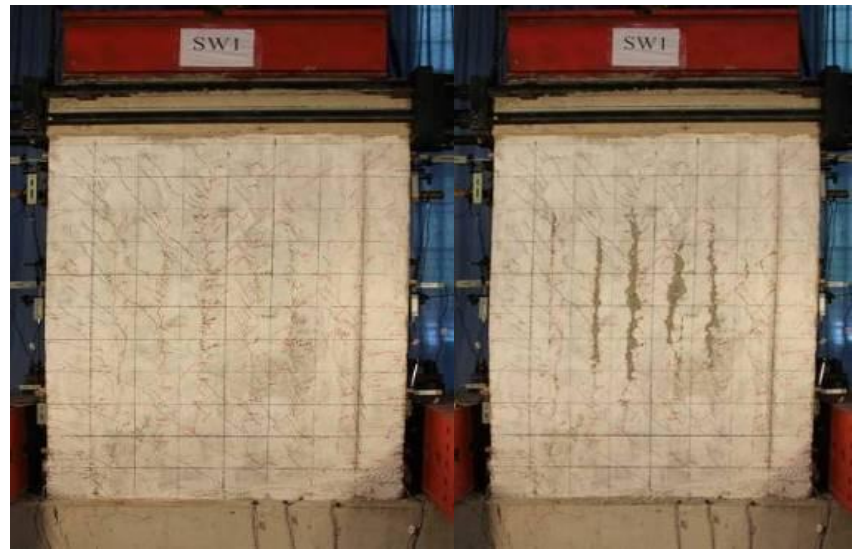

a. Crack pattern at peak load

b. The drift ratio $1 / 100$

Fig. (8). Failure process and pattern of SW1.

columns was less obvious that of SW1, namely, SW1 exhibited a better ductility than 2-SW1.

Fig. (9 and 10) show the crack patterns of two specimens when the drift ratio reached $1 / 100,1 / 80$ and $1 / 60$ respectively. Fig. (11) shows the inner failure patterns of walls. Concrete in the precast slab of 2-SW1 had been crushed when the drift ratio reached 1/60, at the same time, that of SW1 was relatively intact. Concrete between longitudinal holes (namely the longitudinal force transferring

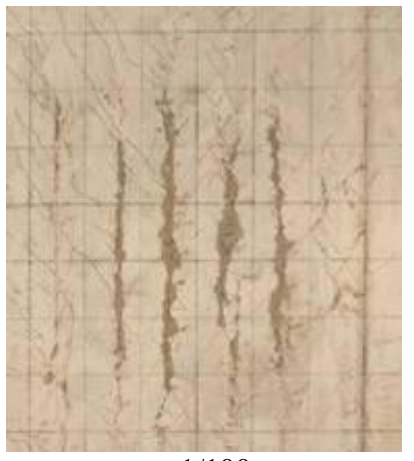

a. $1 / 100$

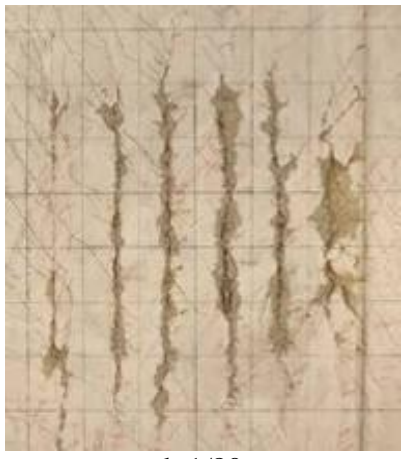

b. $1 / 80$

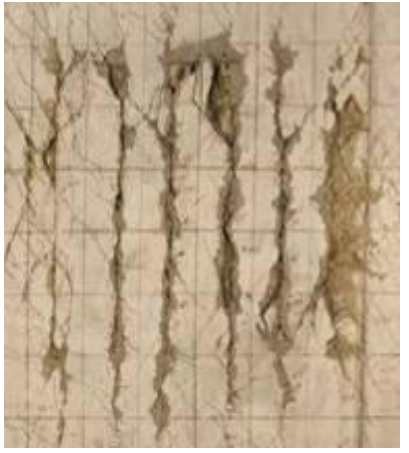

c. $1 / 60$

Fig. (9). Failure behaviors of SW1 at three drift ratios. 


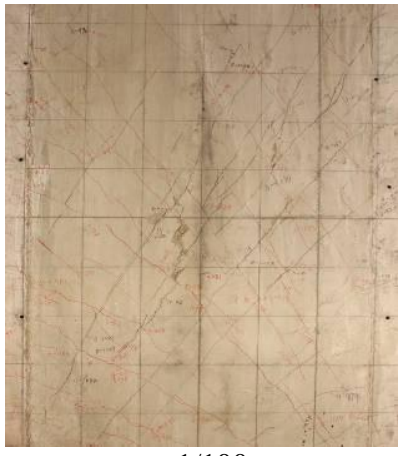

a. $1 / 100$

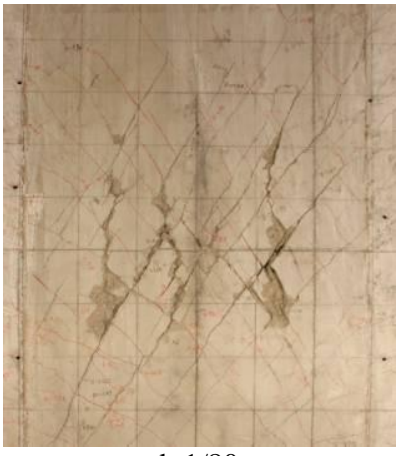

b. $1 / 80$

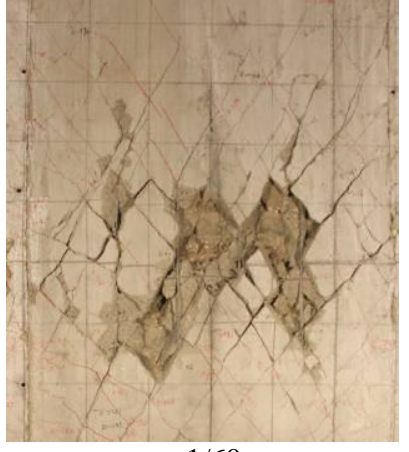

c. $1 / 60$

Fig. (10). Failure behaviors of 2-SW1 at three drift ratios.

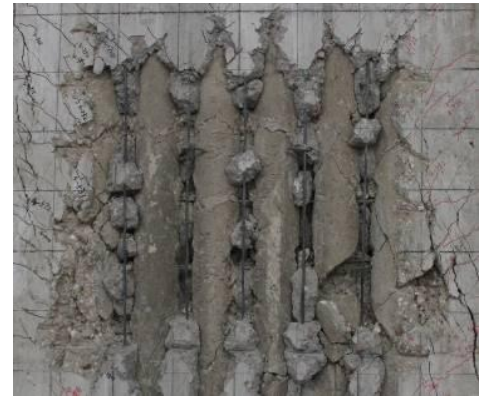

a.Slab A(SW1)

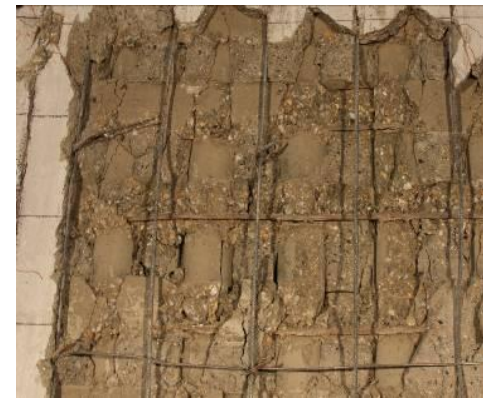

b.Slab B(2-SW1)

Fig. (11). Inner failure pattern of specimens.

paths) of hollow slab B (2-SW1) were broke completely by transverse holes, however, that of hollow slab A (SW1) were relatively continuous, namely, the longitudinal force
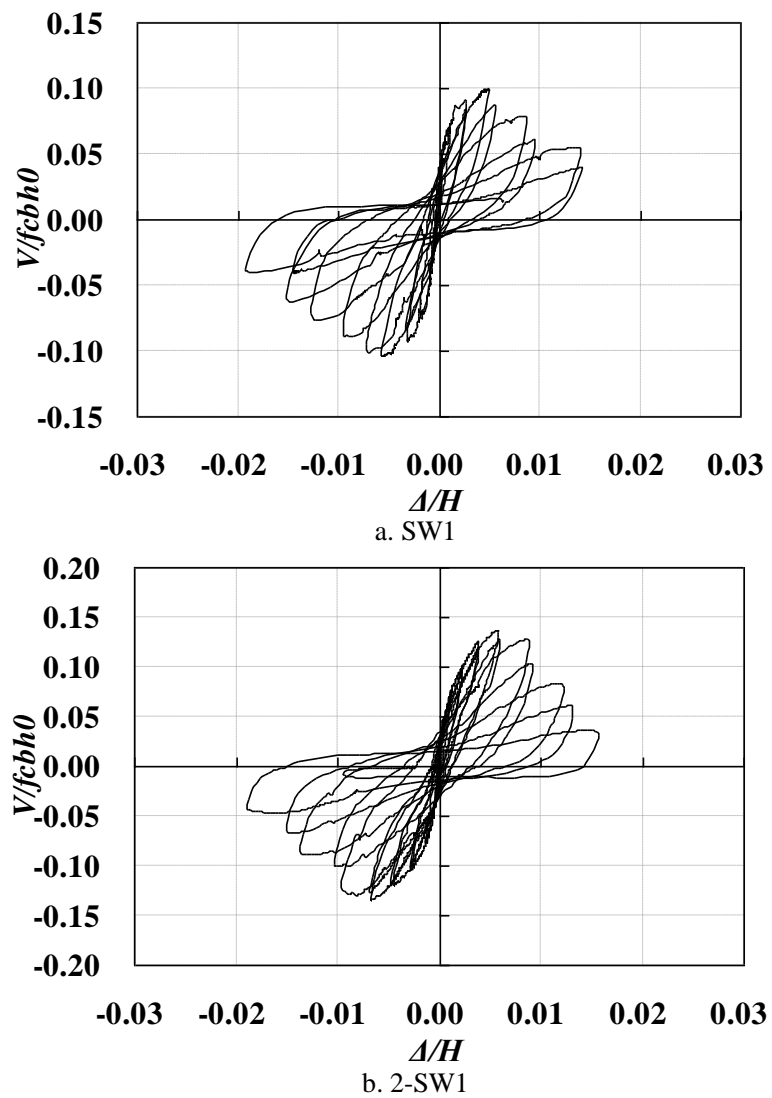

Fig. (12). Hysteretic loops of specimens. transferring paths were not broken. It indicates that when the dimension of transverse holes is larger than that of longitudinal holes, continuity of concrete between longitudinal holes in precast slabs can affect the compressive capacity of walls.

The top lateral force-displacement hysteretic loops and skeleton curves of specimens are shown in Fig. (12) and Fig. (13), where the horizontal axis is the drift ratio measured at the loading point, and the vertical axis is the shear compression ratio $V / f_{c} b h_{0}$. From the curves, it could be found that:

1. Hysteretic loops of the two specimens had a similar shape which was average plump before peak value, yet gradually pinched after that. Both of them exhibited good ductility in terms of their residual deformations increased rapidly at the descending stage of the lateral load.

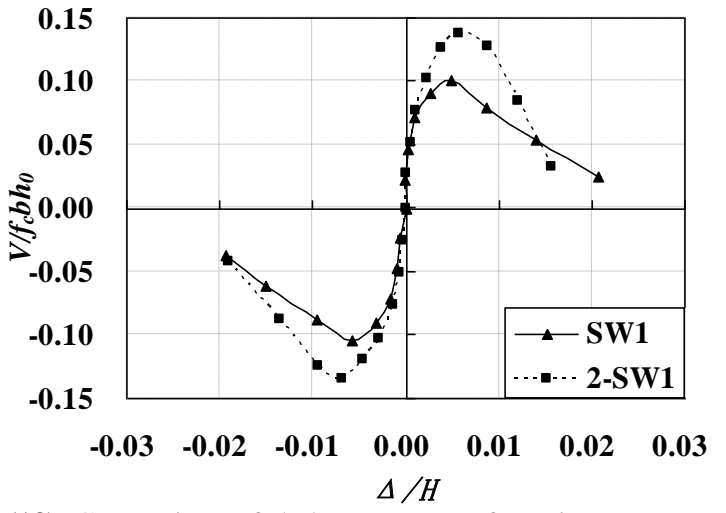

Fig. (13). Comparison of skeleton curves of specimens. 
2. The lateral load-bearing capacity of 2-SW1 deceased rapidly, while the axial compressive capacity was no longer stable after peak point. It again indicates that the compressive capacity of walls can be affected due to the dimension of transverse holes is larger than that of longitudinal holes.

\section{CONCLUSION}

Two PTHSWs with different details of hollow slabs were quasi-statically tested under low cyclic lateral loading. The study shows that:

1. PTHSW structure is a good precast shear wall structure which can be used in practical engineering. Vertical macro-cracks formed under loading which make the failure behavior of walls change from integral wall to the combination of wall-columns. The brittle shear failure can be avoided effectively.

2. Different hollow slabs can affect the development of vertical macro-cracks: vertical macro-cracks of SW1 occurred along the weakest points of concrete between longitudinal holes before peak value, however, that of 2 SW1 occurred along longitudinal distributed reinforcement in the precast slab after peak value.

3. Longitudinal force transferring paths are formed by concrete between longitudinal holes in hollow slabs. When the dimension of transverse holes is larger than that of longitudinal holes, it can affect the compressive capacity of walls due to un-continuity of longitudinal force transferring paths.

\section{CONFLICT OF INTEREST}

The authors confirm that this article content has no conflict of interest.

\section{AKNOWLEDGEMENTS}

The authors are grateful to the support of National Science Foundation of China (Grant No. 51378450) and the Project of Shandong Province Higher Educational Science and Technology Program (Grant No. J13LG09).

\section{REFERENCES}

[1] Z. Zhu and Z. Guo, "Seismic test and analysis of joints of new precast concrete shear wall structure", China Civil Eng. J., vol. 45, no. 1, pp. 69-76, 2012.

[2] D. Wang and X. Lv"Progress of study on seismic performance of precast concrete shear wall systems", Struct. Eng., vol. 26, no. 6, pp. 128-135, 2010.

[3] M. Chu, J. Liu, H. Cui, J. Hou, Y. Zhou, Y. Yin, Q. Zhao, "Experimental study on seismic behaviors of assembled monolithic concrete shear walls built with precast two-way hollow slabs with various details", J. Build. Struct. vol. 35, no. 1, pp. 93-102, 2014.

[4] M. Chu, J. Liu, H. Cui, J. Hou, Y. Zhou, Z. Zhang, "Experimental study on shear behaviors of assembled monolithic concrete shear walls built with precast two-way hollow slabs", Eng. Mech., vol. 30, no. 7, pp. 219-229, 2013.

[5] Ministry of Housing and Urban-Rural Development of the People's Republic of China. "Code for design of concrete structures GB50010-2010," Beijing: China Building Industry Press, 2010.

(C) Zhao et al.; Licensee Bentham Open.

This is an open access article licensed under the terms of the Creative Commons Attribution Non-Commercial License (http://creativecommons.org/licenses/ by-nc/3.0/) which permits unrestricted, non-commercial use, distribution and reproduction in any medium, provided the work is properly cited. 